\title{
The Effect of Gold Salt Concentration in the Production of Gold Nanospheres
}

\author{
Sabreen Juda Badi' ${ }^{1}$, Emad K. Al-Shakarchi' ${ }^{1}$, Shyma'a Jamal Ahmed ${ }^{2}$ \\ ${ }^{1}$ Physics Department, College of Science, Al-Nahrain University, Baghdad, Iraq \\ ${ }^{2}$ College of Medicine, University of Baghdad, Baghdad, Iraq \\ Email: eks2000@hotmail.com
}

How to cite this paper: Badi, S.J, Al-Shakarchi, E.K. and Ahmed, S.J. (2020) The Effect of Gold Salt Concentration in the Production of Gold Nanospheres. Journal of Applied Mathematics and Physics, 8, 1487-1495.

https://doi.org/10.4236/jamp.2020.88114

Received: February 28, 2020

Accepted: August 10, 2020

Published: August 13, 2020

Copyright $\odot 2020$ by author(s) and Scientific Research Publishing Inc. This work is licensed under the Creative Commons Attribution International License (CC BY 4.0).

http://creativecommons.org/licenses/by/4.0/

\begin{abstract}
The optical, electrical and chemical properties of the gold nanospheres synthesized by different gold concentrations in deionized water through a simple chemical reduction method (Turkevich method) were studied. They were dependent on the variation of the gold salt concentration. The peaks of the surface Plasmon resonance (SPR) absorption band and their wavelengths were detected by a UV-visible spectrophotometer. The diameters of the spherical gold nanoparticles were measured theoretically using UV-visible absorption spectrum analysis of the synthesized gold nanoparticles in colloidal form by calculating the ratio of the absorbance at the surface Plasmon resonance (SPR) peak to the absorbance at the lowest peak closed to SPR peak. The values of the gold nanoparticles diameters were $(23 \mathrm{~nm})$ and decreased to $(13 \mathrm{~nm})$ as the function of molarity changed in the range $(0.1-0.3 \mathrm{mM})$. They were compared with the results of the transmission electron microscopy (TEM), which was about (15 - $20 \mathrm{~nm}$ ) measured by the reference images of Sigma-Aldrich values. The conductivity measurements showed increasing the conductivity with molarity increased. The total dissolved solids (TDS) exhibited increase by linear relation with molarity increasing. The $\mathrm{pH}$-value of the gold nanoparticles solutions varied with the molarity and recorded a bowing value of $\mathrm{pH}$-value at $(0.2 \mathrm{mM})$.
\end{abstract}

\section{Keywords}

Gold Nanoparticles, Turkevich Method, Surface Plasmon Resonance, Total Dissolved Solids, Conductivity Measurements

\section{Introduction}

The nanotechnology is more beneficial in many applications specifically in the medical field as nanomedicine in therapy and diagnosis of cancer [1]. The cancer 
is a state of abnormal cell growth as the malignant tumor or malignant neoplasm, with a potential to invade other cells or organs in the body [2]. The most common types of cancers are stomach, lung, breast, colon-rectum, prostate, cervix uteri, mouth, pharynx, liver and esophagus. Its intricacy relies on being a class or group of combined diseases which makes it extremely challenging to find a single cure and target a specific tissue [3] [4]. The current cancer therapy approaches are based on surgery, radiotherapy and chemotherapy where the latter is the one that shows the greater efficacy for treatment, expressly in advanced stages [5]. Many materials have been used in nanotechnology for cancer diagnosis and therapy [6]. The gold nanoparticles (GNPs) are the most compatible nanomaterial for the preparation of engineered nanoplatforms in smart sensing devices. The surface plasmon resonance of GNP makes them the most suitable engineered nanomaterial for bioimaging, biomedical therapeutics and biodiagnostic tools [7]. They are named as gold colloids, and have attracted increasing attention due to their unique properties in multi-disciplinary research fields [8] [9].

The gold nanoparticles are sensitively strong with the light by their environment, size and physical dimensions. The oscillating electric fields of a light ray propagating near a colloidal nanoparticle interact with the free electrons causing a concerted oscillation of electron charge that is in resonance with the frequency of visible light. These resonant oscillations are known as surface plasmon resonance. The small monodispersed gold nanoparticles are about $(\sim 30 \mathrm{~nm})$. The surface plasmon resonance phenomenon is producing a light absorption in blue-green portion of the spectrum at frequency of about $(\sim 450 \mathrm{~nm})$. While, the red light at $(\sim 700 \mathrm{~nm})$ is reflected, yielding a rich red color. As particle size increases, the wavelength of surface plasmon resonance related absorption shifts to longer, redder wavelengths. Red light is then absorbed, and blue light is reflected, yielding solutions with a pale blue or purple color as shown in Figure 1. As the particle size increases toward the bulk limit, surface plasmon resonance wavelengths move to the IR spectrum and most visible wavelengths are reflected, giving the nanoparticles clear or translucent color. The surface plasmon resonance can be tuned by varying the size or shape of the nanoparticles, leading to particles with tailored optical properties for different applications.

The nanotechnology and nanomaterials have attracted large attention in diverse research areas. In recent years, the gold nanoparticles have been used in different fields owing to their unique optical and electrical properties [10] [11]. The gold nanoparticles (GNPs) are defined as stable colloidal solutions of cluster gold atoms with sizes ranging from one to a hundred nanometers. The nanospherical gold possesses different physical and chemical characteristics rather than the bulk one [12] [13].

In the medical field, the advantages of gold nanostructure in size depend on surface Plasmon resonance (SPR), easy-surface functionalization and strong $\mathrm{X}$-ray absorption make GNPs particularly useful in a radiation therapy, photo thermal therapy and biosensors [11]. The spectrum of surface plasmon absorption 


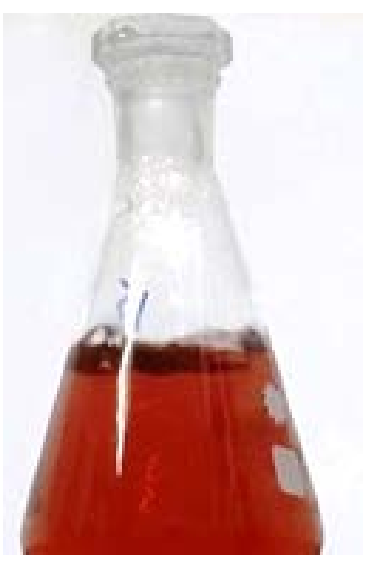

Figure 1. Color of gold nanoparticles solutions.

does not depend on the size but also on the shape of gold nanostructures. When the shape of the gold nanostructure changes from nanospheres to nanorods, the surface Plasmon absorption spectrum also changes [14]. In the case of gold nanosphere shape, the spectrum has a strong absorption band around $(520 \mathrm{~nm})$ at the resonant frequency with the coherent electron motion in the conduction band of the gold nanoparticles [15]. The preparation of uniform gold nanoparticles (AuNPs) is one of the most common procedure in the chemical reduction method (Turkevich method) by the presence of $\mathrm{Au}^{3+}$ aqueous solution due to citrate ions near the boiling point $\left(\sim 100^{\circ} \mathrm{C}\right)$ to produce gold nanoparticles in the form of a stable solution [16].

\section{Materials and Methods}

The colloidal nano-gold was prepared by the reduction method called Turkevich method [17]. $50 \mathrm{ml}$ beakers were cleaned gently with double distilled water, then different molarities of gold chloride tetra hydride $\left(\mathrm{HAuCl}_{4} \cdot 4 \mathrm{H}_{2} \mathrm{O}\right)$ solutions were added to the beakers. These molarities were $(0.1,0.15,0.2,0.25$ and 0.3$)$ respectively. These solutions were heated on a hot plate and magnetic stirrer combination until it reached to $98^{\circ} \mathrm{C}$ temperature. At this temperature, $1 \mathrm{ml}$ of $17 \mathrm{mM}$ trisodium citrate solution was added quickly while observing the colors of the final solutions which were a ruby red colored of nano-gold particles that appeared. The reduction time was 10 minutes for all the experiments and the final solution of the gold nanoparticles was a ruby red colored solution. Two techniques were used to emphasize the presence of gold nanostructure, such as UV-visible absorption spectrum, and transmission electron microscope (TEM). Then using $4 \mathrm{ml}$ quartz cavity filled by a colloidal nanogold solution for UV-visible. A drop of nanogold solution was evaporated onto a carbon-coated copper grid and allowed to dry for the transmission electron microscope analysis.

\section{Results and Discussion}

After the successful preparation of nano-gold solutions with different concentra- 
tions, the UV-Visible absorption spectrum is the tool to show the surface Plasmon resonance. The absorption spectrum exhibited the presence of nanoparticle of a gold solution as shown in Figure 2. The difference in the spectrum appeared in the concentrations of the nano-gold solution in the range $(0.1-0.3 \mathrm{mM})$ by step $0.5 \mathrm{mM}$. The peak position of the surface Plasmon resonance was in the range (524-520 nm), as mentioned in Figure 3, with different concentrations. This range is limited increasing with the previous one [16] [18]. It is clear the absorption intensity increased with increasing the gold salt molarity.

The output data appear in Table 1 that describes the relationship between the wavelengths of the surface Plasmon resonance peak with the gold nanoparticles size. It describes the dependence on the ratio of the absorption intensity at surface Plasmon resonance peak to the absorption intensity at the lower peak closed to the surface Plasmon peak. The calculated theoretical diameter of the gold nanoparticle is compared with the experimental data gotten from TEM as shown in

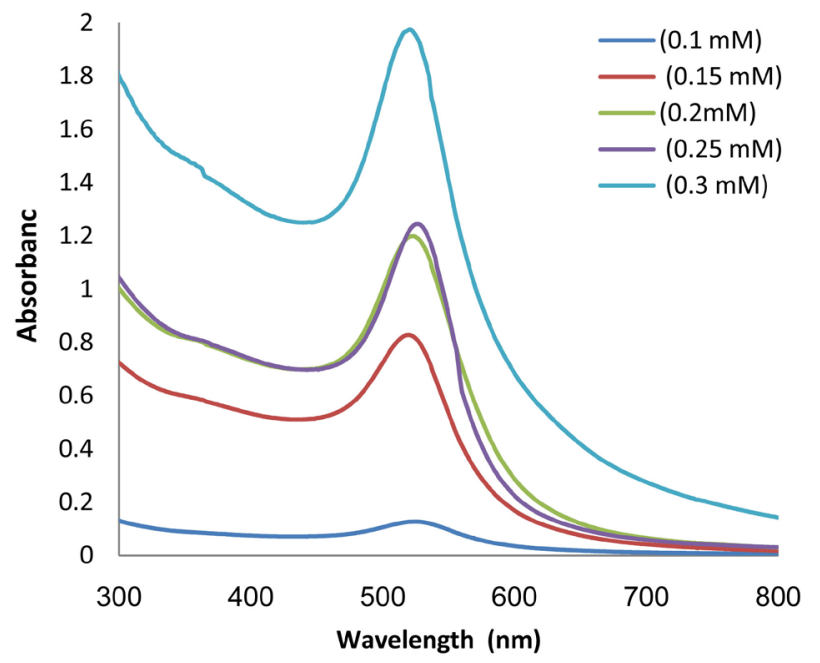

Figure 2. The UV-visible absorption spectra of the gold nanoparticles at different gold salt concentrations.

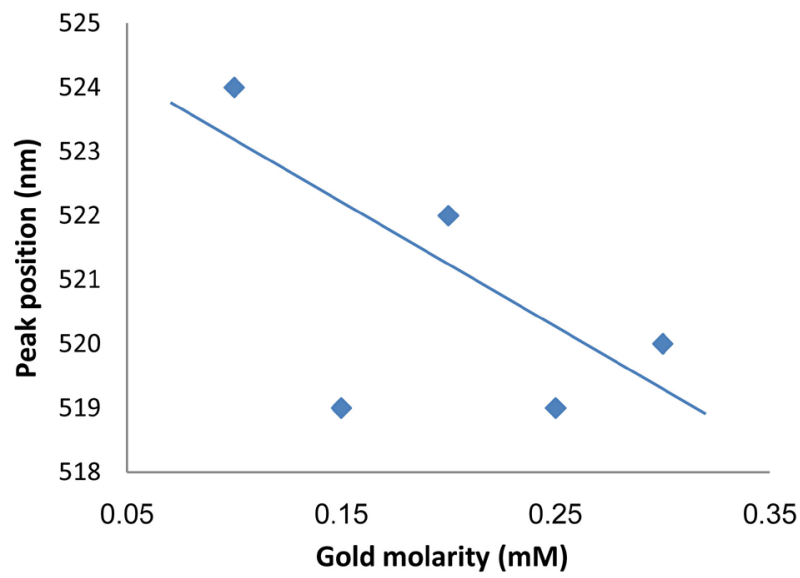

Figure 3. The peak wavelength of the gold nanoparticles as a function of gold salt concentration. 
Table 1. The theoretical calculations and the experimental one of the nanoparticle size.

\begin{tabular}{|c|c|c|c|c|c|c|c|}
\hline $\begin{array}{l}\text { Gold molarity } \\
\qquad(\mathrm{mM})\end{array}$ & $\begin{array}{c}\text { Peak } \\
\text { wavelength }(\mathrm{nm})\end{array}$ & $\begin{array}{l}\text { Absorbance } \\
\text { at SPR peak }\end{array}$ & $\begin{array}{l}\text { Absorbance at } \\
\text { the lowest peak }\end{array}$ & $\begin{array}{l}\text { Absorbance } \\
\text { ratio }\end{array}$ & $\begin{array}{c}\text { Theoretical particle } \\
\text { diameter }(\mathrm{nm})\end{array}$ & $\begin{array}{l}\text { Experimental particle } \\
\text { diameter }(\mathrm{nm})\end{array}$ & $\begin{array}{c}\text { Sigma - Aldrich } \\
\text { values }\end{array}$ \\
\hline 0.1 & 524 & 0.1271 & 0.0710 & 1.7901 & $20-25$ & - & 20 \\
\hline 0.15 & 519 & 0.8278 & 0.5105 & 1.6216 & $14-16$ & 10 & $10-15$ \\
\hline 0.2 & 522 & 1.1992 & 0.6982 & 1.7176 & $18-20$ & - & $15-20$ \\
\hline 0.25 & 519 & 1.1373 & 0.6969 & 1.6319 & $14-16$ & 11 & 10 \\
\hline 0.3 & 520 & 1.974 & 1.2493 & 1.5801 & $12-14$ & - & 15 \\
\hline
\end{tabular}

Figure 4 and Figure 5, and the standard one by Sigma-Aldrich results. The transmission electron microscopy (TEM) is a good technique to observe the size and the shape of the gold nanostructures, as shown in Figure 4 and Figure 5. The general view showed the presence of nanoparticles of gold. It appeared as a spherical shape with average particle size in the range $(10-11 \mathrm{~nm})$, they had high monodispersity. The TEM analysis is matched with Table 1 , for two molarities 0.15 and $0.25 \mathrm{mM}$. They are approaching the standard one concluded by Sigma-Aldrich [18]. On the other hand, the presence of nanoparticles through the accumulation of these nanospheres producing nanobelt, as mentioned in Figure 5. The appearance ratio for the particle size is about $(10-11 \mathrm{~nm})$ with the ratio $41 \%$, and the ratio $15 \%$ for the particle size $(20.74 \mathrm{~nm})$ with the ratio of $15 \%$. This accumulation is more useful in the treatment of cancer cells in the human body, so the production of nanobelt is more efficient than the nanoparticle.

The electrical conductivity of colloidal containing gold nanostructures was studied as a function of different molarity and room temperature, as shown in Figure 6. It is normally the conductivity of colloidal increase as the molarity increased for nanostructure. This is might be attributed to the presence of a high concentration of nanoparticles. This is the reason for the accumulation Au-ions as the molarity increased producing high electrical conductivity at room temperature. The change in the conductivity is tentatively attributed to the ion dissociation from the nanoparticle surface [19]. On the other hand, the total dissolved solids (TDS) is related to the concentration of dissolved solid particles in the solution. The TDS is a combination of all ion particles that are smaller than 2 microns. This includes all of the disassociated electrolytes that make up salinity concentrations, as well as other compounds such as dissolved organic matter. The behavior of TDS as a function of molarity is shown in Figure 7. As the molarity of the gold nanoparticles increased, TDS also increased.

There is a matching between TDS and the conductivity that means a high dissolving of gold ions in the solution tends to make high conductivity. This result is confirmed in Figure 6. While TDS measurements are derived from conductivity, and it often sets a TDS maximum instead of a conductivity limit for water quality. 


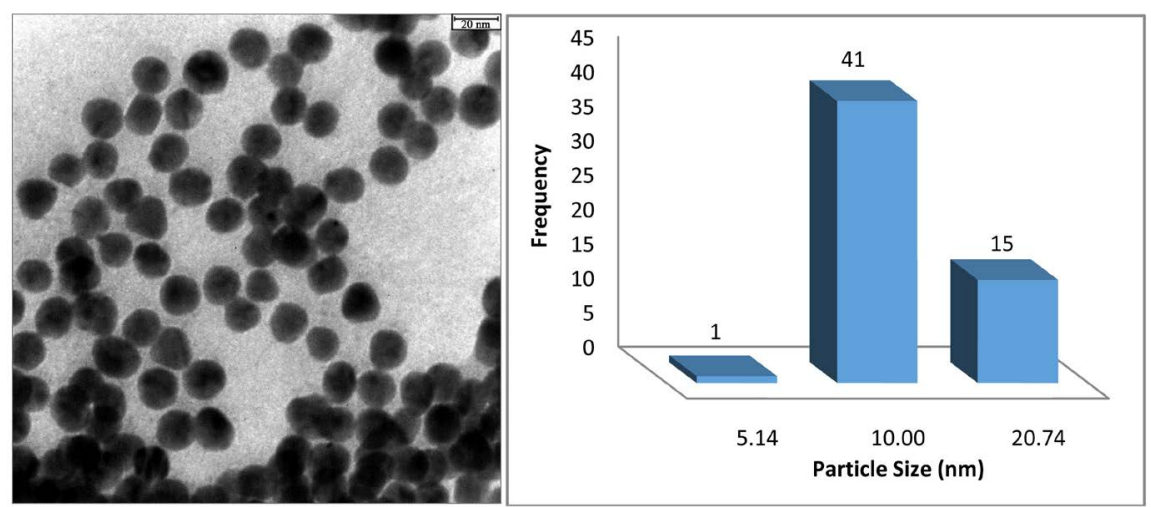

Figure 4. The transmission electron microscope result of the gold nanoparticles at $(0.15$ $\mathrm{mM}$ ) gold salt concentration.
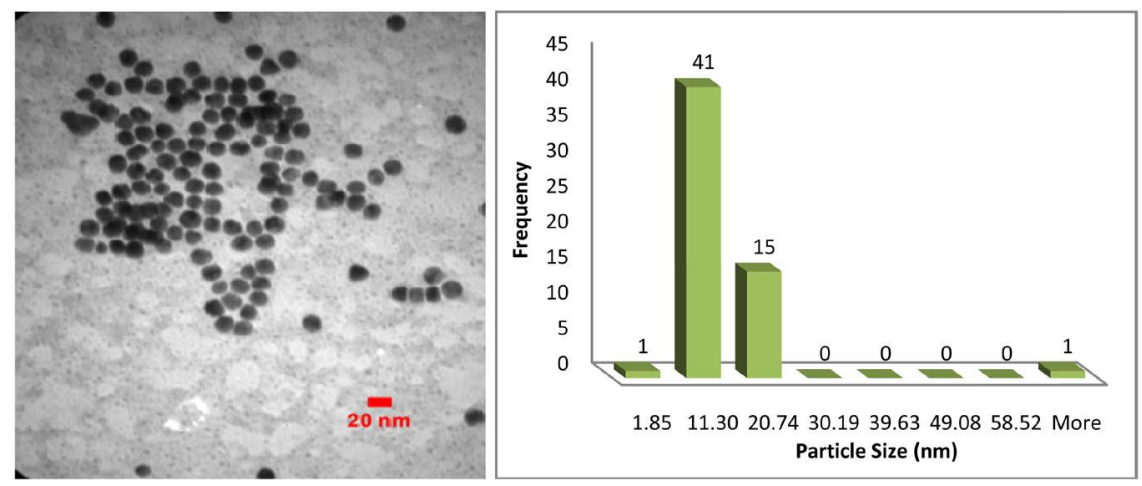

Figure 5. The transmission electron microscope result of the gold nanoparticles at $(0.25$ $\mathrm{mM}$ ) gold salt concentration.

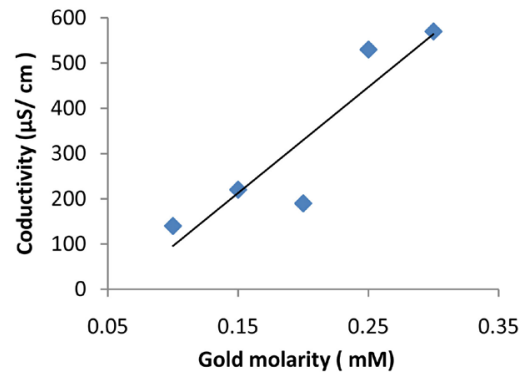

Figure 6. The conductivity of the gold nanoparticles solutions at different molarity and room temperature.

Whereas, measuring of the $\mathrm{pH}$-value is considered the main role in understanding the increase of conductivity and TDS-value as a function of molarity, as mentioned in Figure 8. It describes the power of hydrogen $(\mathrm{pH})$ that is produced in synthesized gold nanoparticles solutions at different molarities. As the gold salt molarity increased, $\mathrm{pH}$ decreased and this attributed to the acidity of the nanogold solution. The varying range of $\mathrm{pH}$-value is (6.2 - 5.4) with the bowing value of about (4.6) appeared at molarity $(0.2 \mathrm{mM})$. The general view of the solution including gold nanoparticle is in the acid shape, which is the reason for increasing the conductivity. 


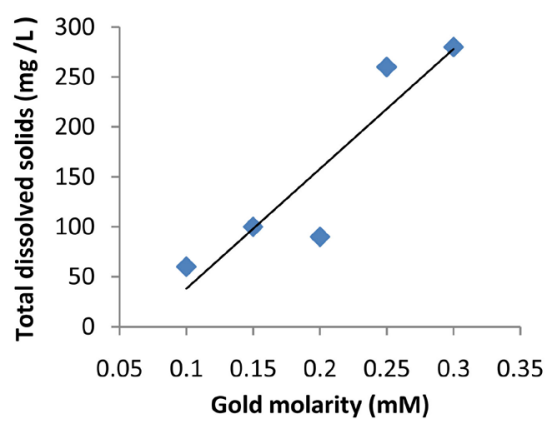

Figure 7. The total dissolved solids (TDS) of the gold nanoparticles solution at different molarity and room temperature.

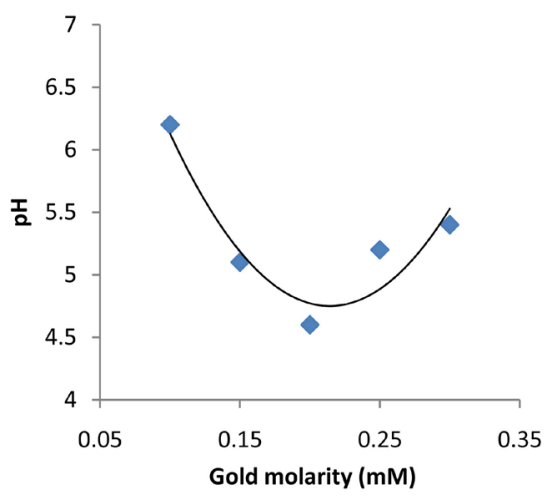

Figure 8. The pH-value of the gold nanoparticles solutions at different molarity and room temperature.

\section{Conclusion}

The preparation of gold nanoparticles makes their accumulation in the solution to produce nanobelt as confirmed by the TEM analysis. The surface plasmon resonance phenomena are the controlling system in the synthesis of gold nanoparticles solution by increasing the concentrations of the gold salt through the molarity. It was noticed that increasing the gold salt molarity leads to increasing the ionic conductivity. The total dissolved solids (TDS) and the conductivity of the nanogold solution depend on the molarity. The $\mathrm{pH}$-value was varied in the acidity range that is the reason for increasing the conductivity. These results are more beneficial in the medical application during the treatment of cancer cells in the human body because the high conductivity makes it easier to accumulate the gold nanoparticle making a wall like or creating nanobelt.

\section{Conflicts of Interest}

The authors declare no conflicts of interest regarding the publication of this paper.

\section{References}

[1] Service, R.F. (2003) Nanomaterials Show Signs of Toxicity. Science, 300, 243. https://doi.org/10.1126/science.300.5617.243a 
[2] Jemal, A., Bray, F., Center, M.M., Ferlay, J., Ward, E. and Forman, D. (2011) Global Cancer Statistics. CA: A Cancer Journal for Clinicians, 61, 69-90. https://doi.org/10.3322/caac.20107

[3] Siegel, R., Naishadham, D. and Jemal, A. (2013) Cancer Statistics. CA: A Cancer Journal for Clinicians, 63, 11-30. https://doi.org/10.3322/caac.21166

[4] Anand, P., Kunnumakkara, A.B., Sundaram, C., Harikumar, K.B., Tharakan, S.T., Lai, O.S., Sung, B. and Aggarwal, B.B. (2008) Cancer Is a Preventable Disease Properties and Implementations in Cancer Diagnosis and That Requires Major Lifestyle Changes. Pharmaceutical Research, 25, 2097-2116.

https://doi.org/10.1007/s11095-008-9661-9

[5] Levy-Nissenbaum, E., Radovic-Moreno, A.F., Wang, A.Z., Langer, R. and Farokhzad, O.C. (2008) Nanotechnology and Aptamers: Applications in Drug Delivery. Trends in Biotechnology, 26, 442-449. https://doi.org/10.1016/j.tibtech.2008.04.006

[6] Brewer, S.H. and Franzen, S. (2002) Indium Tin Oxide Plasma Frequency Dependence on Sheet Resistance and Surface Adlayers Determined by Reflectance FTIR Spectroscopy. The Journal of Physical Chemistry B, 106, 12986-12992.

https://doi.org/10.1021/jp026600x

[7] Jain, P.K., Lee, K.S., El-Sayed, I.H. and EL-Sayed, M.A. (2006) Calculated Absorption and Scattering Properties of Gold Nanoparticles of Different Size, Shape, and Composition: Application in Biological Imaging and Biomedicine. The Journal of Physical Chemistry B, 110, 7238-7248. https://doi.org/10.1021/jp057170o

[8] Daniel, M.C. and Astruc, D. (2004) Gold Nanoparticles: Assembly, Supramolecular Chemistry, Quantum-Size-Related Properties and Applications toward Biology, Catalysis, and Nanotechnology. Chemical Reviews, 104, 293-346. https://doi.org/10.1021/cr030698+

[9] Sardar, R., Funston, A.M., Mulvaney, P. and Murray, R.W. (2009) Gold Nanoparticles: Past, Present, and Future. Langmuir, 25, 13840-13851. https://doi.org/10.1021/la9019475

[10] Xie, J., Zheng, Y. and Ying, J.Y. (2009) Protein-Directed Synthesis of Highly Fluorescent Gold Nanoclustors. Journal of the American Chemical Society, 131, 888-889. https://doi.org/10.1021/ja806804u

[11] Guo, M., Sun, Y. and Zhang, X.-D. (2017) Enhanced Radiation Therapy of Gold Nanoparticles in Liver Cancer. Applied Sciences, 7, 232. https://doi.org/10.3390/app7030232

[12] Park, J.H., Lim, Y.T., Park, O.O., Kim, J.K., Yu, J.W. and Kim, Y.C. (2004) Polymer/Gold Nanoparticle Nanocomposite Light-Emitting Diodes: Enhancement of Electroluminescence Stability and Quantum Efficiency of Blue-Light-Emitting Polymers. Chemistry of Materials, 16, 688-692. https://doi.org/10.1021/cm0304142

[13] Naraynan, R. and Al-Sayed, M.A. (2005) Catalysis with Transition Metal Nanoparticles in Colloidal Solution: Nanoparticle Shape Dependence and Stability. Journal of Physical Chemistry B, 109, 12663-12676. https://doi.org/10.1021/jp051066p

[14] Link, S. and El-Sayed, M.A. (2003) Optical Properties and Ultrafast Dynamics of Metallic Nanocrystals. Annual Review of Physical Chemistry, 54, 331-336. https://doi.org/10.1146/annurev.physchem.54.011002.103759

[15] Huang, X. and El-Sayed, M.A. (2010) Gold Nanoparticles: Optical Properties and Implementations in Cancer Diagnosis and Photothermal Therapy. Journal of Advanced Research, 1, 13-28. https://doi.org/10.1016/j.jare.2010.02.002

[16] Ngumbi, P.K., Mugo, S.W. and Ngaruiya, J.M. (2018) Determination of Gold Nanoparticles Sizes via Surface Plasmon Resonance. IOSR Journal of Applied Chemi- 
stry, 11, 25-29.

[17] Rohiman, A., Anshori, I., Surawijaya, A. and Idris, I. (2011) Study of Colloidal Gold Synthesis Using Turkevich Method. AIP Conference Proceedings, 1415, 39-42. https://doi.org/10.1063/1.3667215

[18] Rahman, S. (2016) Size and Concentration Analysis of Gold Nanoparticles with Ultraviolet-Visible Spectroscopy. Undergraduate Journal of Mathematical Modeling, 7, 1-13. https://doi.org/10.5038/2326-3652.7.1.4872

[19] Zhang, Y., Schwartzberg, A.M., Xu, K., Gu, C. and Zhang, J.Z. (2005) Electrical and Thermal Conductivities of Gold and Silver Nanoparticles in Solutions and Films and Electrical Field Enhanced Surface-Enhanced Raman Scattering (SERS). Physical Chemistry of Interfaces and Nanomaterials, Proceedings of SPIE, 5929, Article ID: 592912. https://doi.org/10.1117/12.614499 